Supplement of Biogeosciences, 16, 2467-2479, 2019

https://doi.org/10.5194/bg-16-2467-2019-supplement

(C) Author(s) 2019. This work is distributed under

the Creative Commons Attribution 4.0 License.

(c) (1)

Supplement of

\title{
Biomarker evidence for the occurrence of anaerobic ammonium oxidation in the eastern Mediterranean Sea during Quaternary and Pliocene sapropel formation
}

Darci Rush et al.

Correspondence to: Darci Rush (darci.rush@nioz.nl)

The copyright of individual parts of the supplement might differ from the CC BY 4.0 License. 

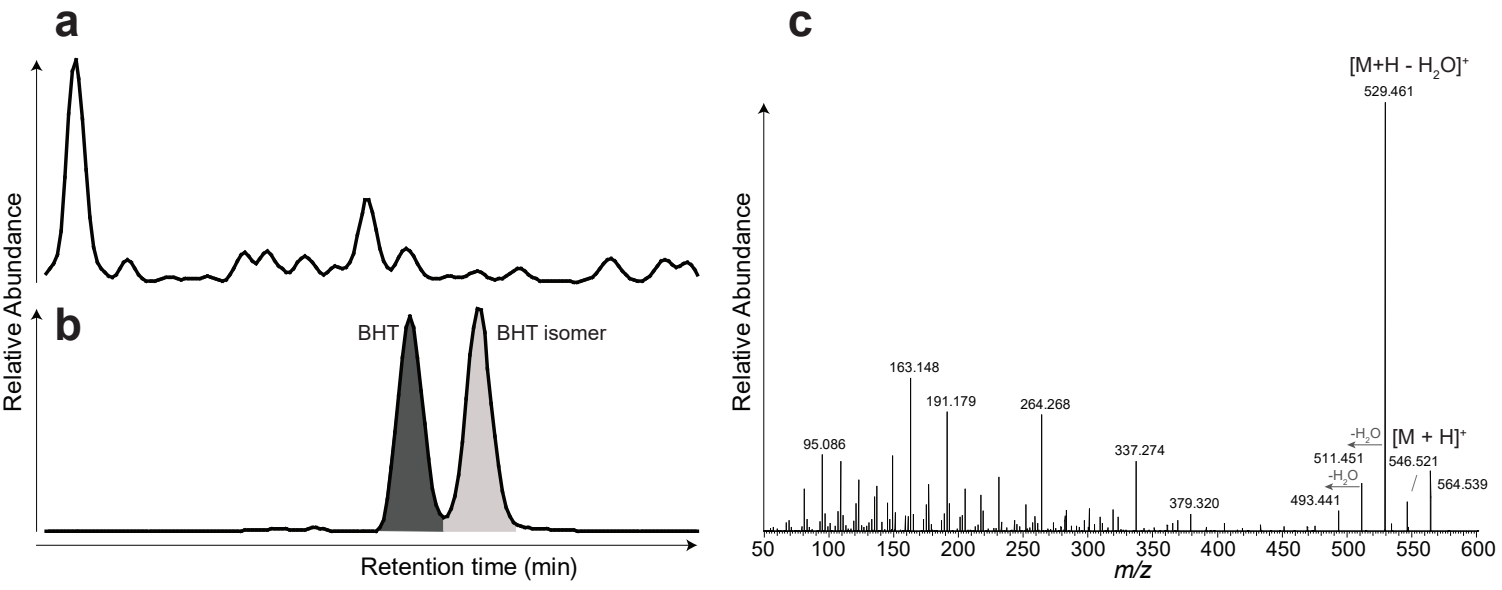

Supplemental Figure 1. High resolution MS analysis of 64PE406-E1 core depth $46-47 \mathrm{~cm}$. (a) Base peak chromatogram, (b) combined extracted ion currents (within $3 \mathrm{ppm}$ ) of protonated, ammoniated, and sodiated adducts ( $/ \mathrm{z} 5547.472+564.499+569.454$, respectively) of non-derivatised BHT and BHT isomer, (c) averaged orbitrap HRMS2 $(n=6)$ of the BHT isomer ammoniated adduct ([M+NH4]+; m/z 564.499). 